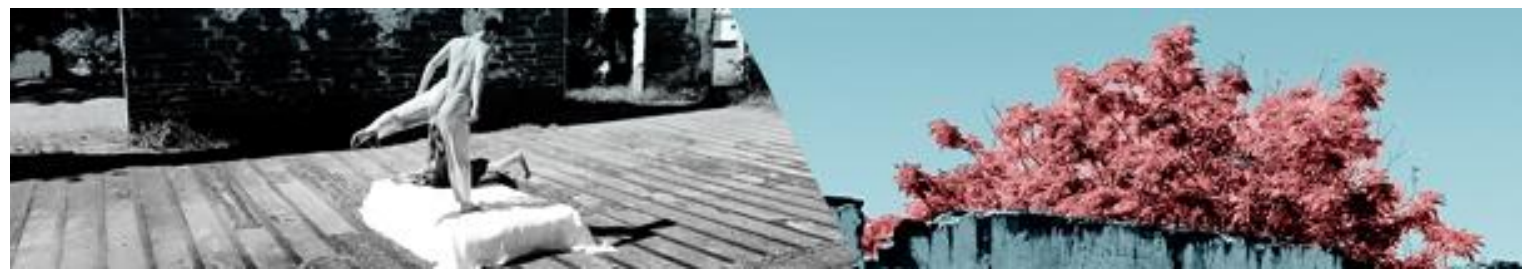

\title{
A DANÇA E AS RELAÇÕES DE GÊNERO: UMA REFLEXÃO SOBRE A INTERAÇÃO ENTRE MENINOS E MENINAS EM UMA AULA DE DANÇA
}

\section{Giuliano Souza Andreoli1} Larissa Canelhas²

Resumo: Nesse artigo apresentamos uma pesquisa cujo objetivo foi compreender como a aula de dança pode se configurar em espaço de experiências generificantes. Utilizamos para isto o conceito de gênero. Através da análise de observações realizadas em aulas de dança do projeto PIBID, realizado pela Universidade Estadual do Rio Grande do Sul, as reflexões transitam pelos cenários nos quais as relações de gênero se constituíram, implicando no pensar e no fazer dança. Os resultados apontam que há hierarquizações entre os meninos e as meninas no contexto das aulas de dança, bem como formas generificadas de organização das práticas de dança, mas que algumas mudanças na intervenção dos(as) professores(as) já começam a acontecer.

Palavras-chave: dança; gênero; educação.

\section{DANCE AND GENDER RELATIONS: A REFLECTION ON THE INTERACTION BETWEEN BOYS AND GIRLS IN A DANCE CLASS}

\begin{abstract}
In this article we present a research whose objective was to understand how the dance class can be configured in space of genderificated experiences. We use the concept of gender. Through the analysis of observations made in dance lessons of the PIBID project, carried out by the State University of Rio Grande do Sul, the reflections go through the scenarios in which the gender relations were constituted, implying thinking and doing dance. The results point out that there are hierarchies between boys and girls in the context of dance classes, as well as generalized forms of organization of dance practices, but that some changes in the intervention of the teachers already begin to happen.
\end{abstract}

Key-words: dance; gender; education.

\footnotetext{
1 Possui graduação em Educação Física (UFRGS), Especialização em Pedagogias do Corpo (UFRGS), e Mestrado em Educação (UFRGS). Atua na área de Teoria da Dança, com ênfase na relação entre Dança e Educação, Dança e Ciências Humanas (Antropologia, Sociologia, História, Estudos Culturais, Estudos de Gênero). É professor do Curso de Graduação em Dança: Licenciatura da Universidade Estadual do Rio Grande do Sul (UERGS). Atua principalmente nas disciplinas: Teoria da Dança, Dança e Cultura I e II, História da Dança I e II, Educação e Pluralidade Cultural e Técnicas corporais Circenses.

2 Larissa Canelhas é graduada em Dança: Licenciatura pela Universidade Estadual do Rio Grande do Sul/ UERGS. Foi Bolsista pelo Programa Institucional de Bolsas de Iniciação a Docência. Participou da Residência Artística "Do perigo de se contar uma única história" do Projeto: "Espaços Sobre as Pequenas Distâncias. Estudos para o Infinito" no Centro de Referência da Dança de São Paulo. É integrante do Coletivo Órbita onde atua como bailarina intérprete criadora e professora.
}

ANDREOLI, Giuliano Souza; CANELHAS, Larissa. A dança e as relações de gênero: uma reflexão sobre a interação entre meninos e meninas em uma aula de dança. Revista da FUNDARTE, Montenegro, p.375-394, ano 19, no 37, Janeiro/Março.

Disponível em: http://.seer.fundarte.rs.gov.br/index.php/RevistadaFundarte/index> 30 de março de 2019. 


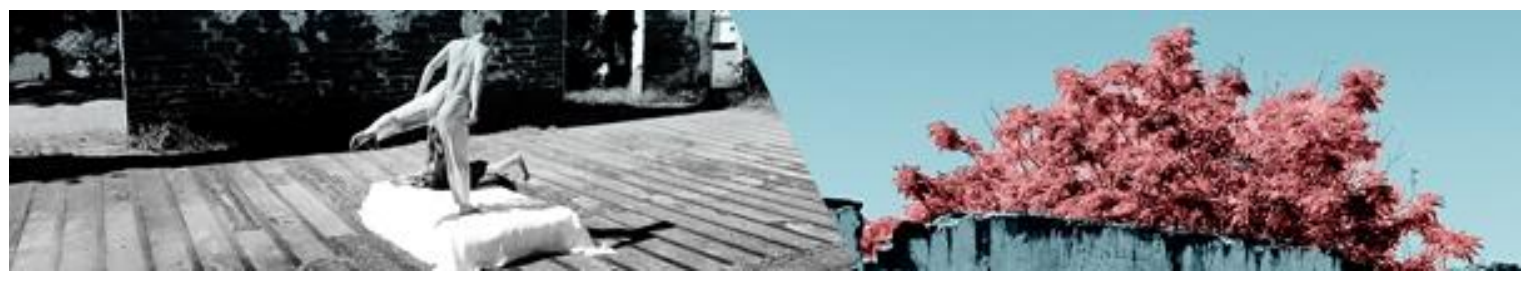

A pesquisa que subsidia este trabalho foi desenvolvida com o objetivo de observar e analisar a constituição generificada de corpos e posições de sujeito de alunos e alunas em um currículo escolar dos anos iniciais do ensino fundamental. As aulas foram ministradas por estudantes de graduação, de um curso de licenciatura em dança, vinculados ao programa Institucional de Bolsa de Iniciação à Docência (PIBID) do Campus de Montenegro II da Universidade Estadual do Rio Grande do Sul (UERGS).

Sendo assim, em primeiro momento este artigo apresentará o conceito de gênero. Em segundo momento, o foco estará na relação entre dança e educação. Em terceiro momento, apresentarei a metodologia, o campo e os objetivos dessa pesquisa. Por fim, apresentarei os resultados das observações realizadas nas aulas dos bolsistas cadastrados no programa de iniciação à docência no ano de 2017. Analisando algumas situações cotidianas de aulas de Dança, procurarei, a partir desse recorte microscópico, dimensionar a categoria gênero como parte do processo de escolarização de meninos e meninas em aulas de dança.

\section{O CONCEITO DE GÊNERO:}

O termo gênero indica, neste artigo, a construção cultural de significados, símbolos e normas que dão origem às "masculinidades" e "feminilidades" (SCOTT, 1995; BUTLER, 2010; LOURO, 2007). Gênero difere, portanto, de "sexo", tal como é usado nas ciências biológicas, para designar as diferenças biológicas entre homens e mulheres e designa as diferenças sócio-culturais (SCOTT, 1995, LOURO, 2007). É um conceito que opera, portanto, a partir da "rejeição do determinismo biológico implícito nos termos 'sexo' e 'diferença sexual'." (SCOTT, 1995, p. 72).

Para Butler (2010), o sujeito de gênero é um efeito produzido através da repetição de atos correspondentes com as normas sociais e culturais. Por isso, gênero não é a expressão do que homens e mulheres são em sua essência, mas sim a própria performance cultural que permite a manutenção dessas normas, que, por sua vez, instituem, em nossa cultura, uma oposição binária, a partir da lógica

ANDREOLI, Giuliano Souza; CANELHAS, Larissa. A dança e as relações de gênero: uma reflexão sobre a interação entre meninos e meninas em uma aula de dança. Revista da FUNDARTE, Montenegro, p.375-394, ano 19, ํo 37, Janeiro/Março.

Disponível em: http://.seer.fundarte.rs.gov.br/index.php/RevistadaFundarte/index> 30 de março de 2019. 


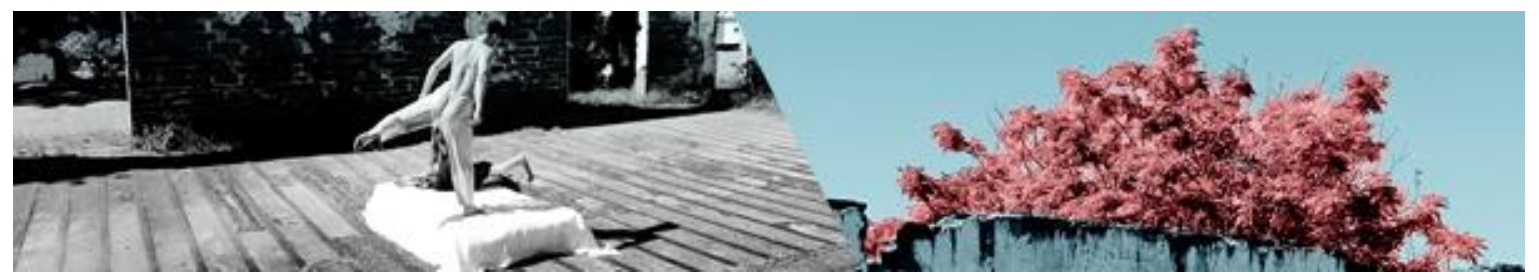

cultural do "falocentrismo": a dicotomia e a hierarquia entre a "masculinidade" e a "feminilidade".

Essa noção já estava presente em Aristóteles, por exemplo, que expressava uma concepção corrente e comum no mundo grego antigo: as mulheres eram homens cujo desenvolvimento tinha parado antes do término, incapazes de atingir a sua forma perfeita porque o frio do útero da mãe fora superior ao calor do sêmen do pai (CORREIA, 2004, p.31). Até o século XVIII, para a Medicina, a mulher era entendida como sendo um homem inferior. O útero era o escroto feminino, os ovários eram os testículos, a vulva era um prepúcio e a vagina era um pênis, todos invertidos. Concebida como um homem invertido, a mulher era um organismo menos desenvolvido na escala da perfeição. O modelo de perfeição era a anatomia masculina. (LAQUEUR, 2001). Como herança dessa lógica cultural, as representações hegemônicas de gênero concebem as masculinidades e as feminilidades com características polarizadas, sendo o masculino o pólo considerado mais valorizado.

Além disso, o gênero é regido, em nossa civilização, pela lógica cultural da heteronormatividade (BUTLER, 2010). Essa pressuposição de que a sexualidade hetero é a "normal", sendo qualquer outra orientação sexual um desvio, é um dos mecanismos da regulação dos gêneros que dá origem à homofobia. Ela é descrita por Britzman como "a obsessão com a sexualidade normalizante, através de discursos que descrevem a situação homossexual como desviante" (BRITZMAN, 1996, p. 79).

Gênero pode, assim, legitimar relações de desigualdade ou até mesmo de violência (concreta ou simbólica), originando desigualdades sociais: a) a desigualdade relacionada ao sexo, isto é, as classificações, hierarquias e exclusões fundadas a partir da distinção binária entre homens e mulheres; e b) a exclusão das sexualidades não-hetero, "desviantes" da lógica heteronormativa. Além disso, como observa, Butler (2001, 2010):

O gênero não deve ser meramente concebido como a inscrição cultural de significado num sexo previamente dado [...] tem de designar também o

ANDREOLI, Giuliano Souza; CANELHAS, Larissa. A dança e as relações de gênero: uma reflexão sobre a interação entre meninos e meninas em uma aula de dança. Revista da FUNDARTE, Montenegro, p.375-394, ano 19, no 37, Janeiro/Março.

Disponível em: http://.seer.fundarte.rs.gov.br/index.php/RevistadaFundarte/index> 30 de março de 2019. 


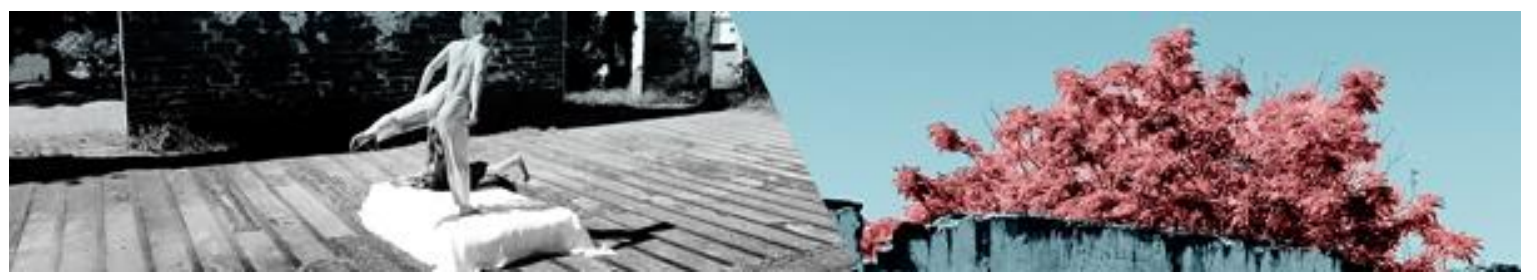

aparato mesmo de produção mediante o qual os próprios sexos são estabelecidos. (BUTLER, 2010, p. 25).

Os discursos convertem determinadas partes dos corpos, tais como os órgãos genitais, em definidores de gênero. Assim, as pessoas 'cisgênero' são aquelas que mantêm um status de privilégio em detrimento das pessoas 'transgênero', por serem socialmente vistas como "alinhadas" dentro de seu corpo e de seu gênero (BUTLER, 2001; LOURO, 2013b; PRECIADO, 2014). Essa relação determinista entre sexo biológico e gênero, impõe a "cisnormatividade". E assim, os transexuais, apreendidos no interior desses dispositivos, são aqueles/as que Butler (2001, p.171), chama de "corpos que não pesam", que não importam e que podem ser descartados.

Essa perspectiva, portanto, questiona a universalidade das categorias "homem" e "mulher", associadas a oposições binárias que associam o poder e a dominação ao masculino e a submissão ao feminino. Gênero é compreendido de forma relacional (SCOTT, 1995). Ele institui relações de poder bem mais complexas, que incluem não só a supremacia de homens sobre mulheres, mas também o consentimento e adesão de mulheres ou a coerção de homens que não se incluem nos padrões dominantes de masculinidade. Nessa perspectiva, o termo gênero implica também em algo que vai além do mero desempenho de "papéis" sociais (LOURO, 2007), pois os discursos que representam e contextualizam as significações de ser homem ou mulher são postos em ação em variados espaços e circunstâncias sociais.

Neste sentido, entende-se que gênero está relacionado com toda a organização de uma sociedade, com as instituições sociais (a educação, o sistema político, etc.), com os conceitos normativos sobre o masculino e o feminino, com os símbolos culturalmente disponíveis, com a economia, com o Estado, etc. (CONNEL, 1995; SCOTT 1995). Tais práticas sociais são instâncias, espaços, campos de saber ou práticas culturais "generificadas". Toda cultura e sociedade são constituídas por representações - sempre múltiplas, provisórias e contingentes - de feminino e masculino, e, ao mesmo tempo, produzem e/ou ressignificam essas representações

ANDREOLI, Giuliano Souza; CANELHAS, Larissa. A dança e as relações de gênero: uma reflexão sobre a interação entre meninos e meninas em uma aula de dança. Revista da FUNDARTE, Montenegro, p.375-394, ano 19, no 37, Janeiro/Março.

Disponível em: http://.seer.fundarte.rs.gov.br/index.php/RevistadaFundarte/index> 30 de março de 2019. 


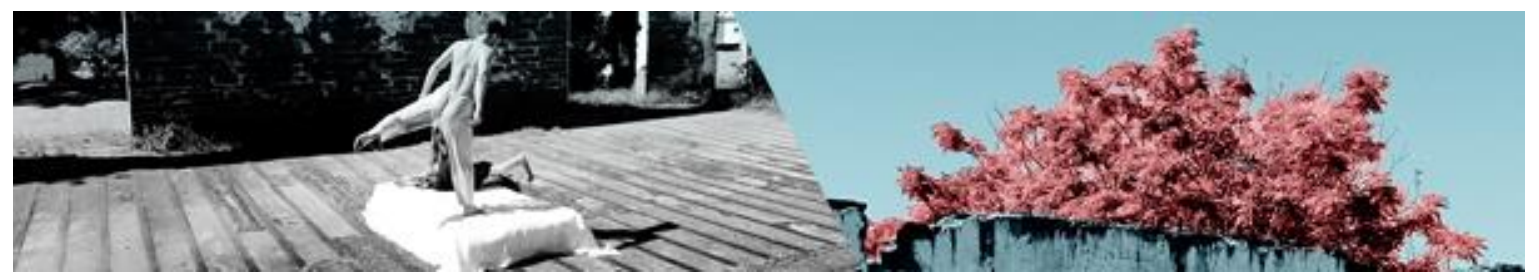

(MEYER, 2004, p.15). Em outras palavras, diferentes práticas sociais reproduzem os valores e significados culturais hegemônicos de gênero, e também os colocam em operação, reforçando-os, "generificando" os indivíduos a partir dessas normas.

Assim como outras categorias sociais, tais como a raça, a etnia ou a classe, o gênero se refere à construção de identidades sociais. E está ligado aos sistemas simbólicos e de classificação criados por meio da linguagem, a partir dos quais os indivíduos se posicionam como sujeitos.

\section{DANÇA, GÊNERO E EDUCAÇÃO:}

Segundo Louro (2013b) e Connel (1995) o processo de educação de homens e mulheres em sociedade implica no processo ensino/aprendizagem de valores, posturas e movimentos corporais considerados masculinos ou femininos. Pensar a relação entre dança e gênero, portanto, implica em problematizarmos a relação entre o corpo e o gênero, haja visto que, segundo o campo dos Estudos de Gênero, nós vivenciamos as nossas masculinidades e feminilidades como "certas tensões musculares, posturas, habilidades físicas, formas de nos movimentar (...)" (CONNEL, 1995, p.189).

Ressaltamos a importância do conceito de "técnicas corporais" que, segundo Mauss (1979), são as formas ritualizadas como os seres humanos tendem a imitar certas maneiras de utilizar o seu corpo. Mauss evidencia que elas nunca estão dissociadas dos valores culturais da sociedade onde o indivíduo é socializado, pois:

[...] variam não simplesmente com os indivíduos e suas imitações, variam, sobretudo, com as sociedades, as educações, as conveniências, as modas e os prestígios. (MAUSS, 1974, p.404).

Dessa maneira, Mauss não se refere apenas a comportamentos corporais imitados de forma consciente, mas também à esfera inconsciente, abarcando tanto processos de aprendizado formal e não formal (incluindo-se aqui o chamado "ensino tradicional de dança", com o seu modelo calcado apenas em cópia e repetição) quanto os processos de aprendizado chamados de informais (ANDREOLI, 2017).

ANDREOLI, Giuliano Souza; CANELHAS, Larissa. A dança e as relações de gênero: uma reflexão sobre a interação entre meninos e meninas em uma aula de dança. Revista da FUNDARTE, Montenegro, p.375-394, ano 19, ํo 37, Janeiro/Março.

Disponível em: http://.seer.fundarte.rs.gov.br/index.php/RevistadaFundarte/index> 30 de março de 2019. 


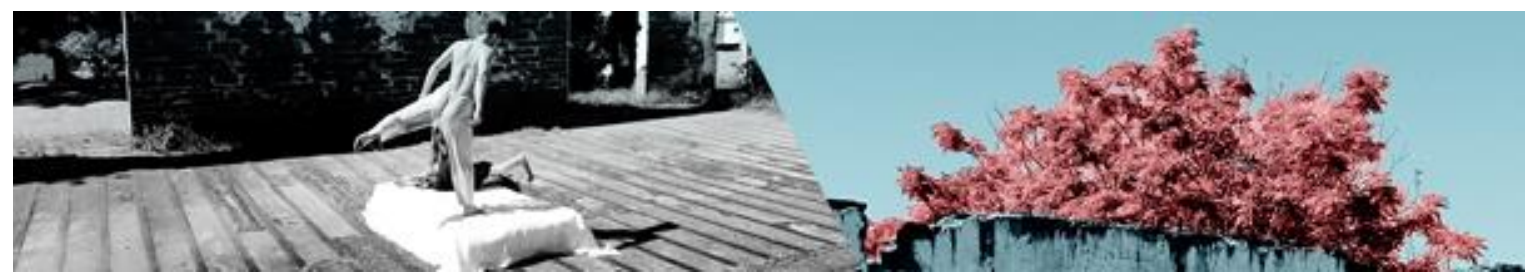

Para Mauss, as técnicas corporais dividem-se e variam, entre outras coisas, de acordo com as expectativas e valores que cada sociedade constrói para cada sexo. Há, assim, uma relação bastante próxima entre este conceito e aquilo que Judith Butler chama de "performance" de gênero, na medida em que o corpo é o "lugar" onde são inscritos os discursos, e onde o gênero é reproduzido enquanto comportamento performativo.

Vários estudos têm apontado que, enquanto o esporte é hegemonicamente significado como uma experiência masculina, relacionado com características de personalidade supostamente viris (COOK et al., 2014), a dança é vista como atividade efeminada e suspeita para um corpo masculino (SANDERSON, 2001; SOUZA, 2007; SANTOS, 2009a; SANTOS 2009b, ANDREOLI, 2011, MIGDALEK, 2015). Por isso, a grande maioria da população que procura por aulas dança nos espaços não formais são mulheres (GREEN, 2001, 2004; SHAPIRO, 2008); e as professoras de dança também são mais numerosas do que os professores (RISNER, 2014).

Devido à dança ser muito vinculada a um ideal de feminino, ou seja, a uma representação hegemônica de gênero, as lições sobre feminilidade aprendidas em aulas de dança, por exemplo, muitas vezes são as mesmas que as meninas aprendem em outros lugares: ser silenciosa, obediente, graciosa e bonita. Assim, muitas aulas de dança reforçam certas expectativas da sociedade em relação às mulheres (STINSON, 1988; SANTOS, 2009b), produzindo subjetividades femininas em conformidade com certas normas de gênero. Por outro lado, as mesmas representações hegemônicas levam à estigmatização e ao bullying dos homens que dançam (POLASEK \& ROPER, 2011; RISNER, 2014).

Embora a dança seja hegemonicamente cosiderada uma atividade feminina, os homens sempre dançaram, ao longo da história. Porém, a generificação de certas danças, ainda hoje, emerge de uma compreensão restrita do que é ser masculino e gera relutância à participação de homens. Um exemplo é o balé, uma dança cujas técnicas corporais são vistas como "femininas" e onde os homens, geralmente, são minoria.

ANDREOLI, Giuliano Souza; CANELHAS, Larissa. A dança e as relações de gênero: uma reflexão sobre a interação entre meninos e meninas em uma aula de dança. Revista da FUNDARTE, Montenegro, p.375-394, ano 19, ํo 37, Janeiro/Março.

Disponível em: http://.seer.fundarte.rs.gov.br/index.php/RevistadaFundarte/index> 30 de março de 2019. 


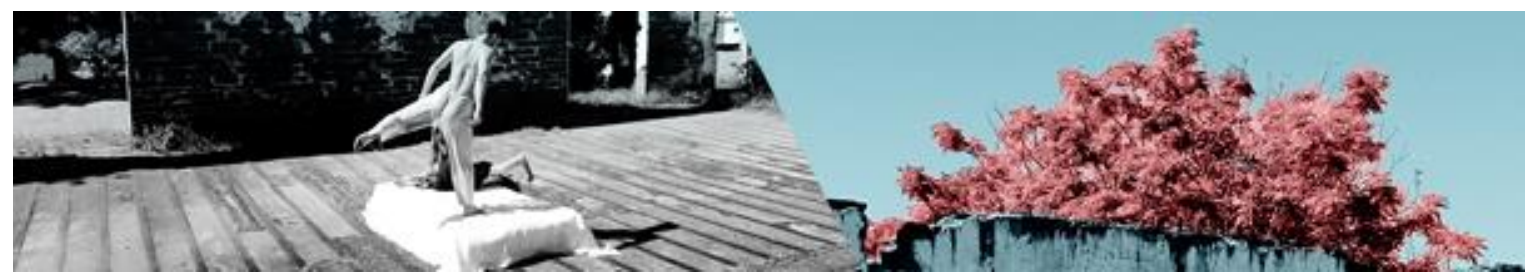

Em outros estilos, o prestígio social adquirido pela execução das técnicas corporais permite legitimar uma identidade masculina, fazendo com que certas danças atraiam mais homens (HOLDSWORTH, 2013). As danças urbanas, por exemplo, podem aumentar a popularidade e a atratividade para os meninos, dada a significação que se faz delas como símbolo de masculinidade (PASCOE, 2005; SANTOS 2009a), o que reforça padrões de técnicas corporais associadas a representações hegemônicas de masculinidade, ligadas a símbolos de dominação, força e virilidade; e também limita ou dificulta a participação feminina (WHELER, 2005).

Duas dimensões, assim, na intersecção entre dança e gênero, revelam uma mútua influência: gênero regula as escolhas de vida das pessoas que dançam; e as danças por eles produzidas veiculam e põe em circulação representações de gênero. Ou seja, a dança é influenciada pelos valores culturais e morais construídos sobre o feminino e o masculino, pelos significados atribuídos ao corpo que dança a partir das representações hegemônicas de gênero e, simultaneamente, coloca em operação esses significados, definindo e regulando aquilo que se entende por desempenho corporal mais ou menos adequado a homens e mulheres, reproduzindo comportamentos, posturas e técnicas corporais associados aos estilos de vida considerados masculinos e femininos. Em suma, a dança é generificada e generificante (ANDREOLI, 2018).

$\mathrm{Na}$ contemporaneidade, desde os anos 70 , surgiram estéticas artísticas contrárias às representações hegemônicas de gênero e corpo na dança. Ocorreu uma troca simbiótica entre as críticas sociais trazidas a partir das mudanças das relações sociais e do avanço dos movimentos sociais (feministas, LGBTQs, Queer) e a produção artística.

[...] as concepções biologizantes por meio das quais se estabelece o binarismo sexual são cada vez mais problematizadas e desconstruídas nas artes da contemporaneidade (...) No entanto, o que de um modo geral podemos acessar enquanto produção artística na dança - e me refiro em especial aos espetáculos de palco - carrega ainda muito do peso histórico dessa construção binária, resquício do romantismo do final do XIX. (BERGHAUSER, 2013, p.6).

ANDREOLI, Giuliano Souza; CANELHAS, Larissa. A dança e as relações de gênero: uma reflexão sobre a interação entre meninos e meninas em uma aula de dança. Revista da FUNDARTE, Montenegro, p.375-394, ano 19, no 37, Janeiro/Março.

Disponível em: http://.seer.fundarte.rs.gov.br/index.php/RevistadaFundarte/index> 30 de março de 2019. 


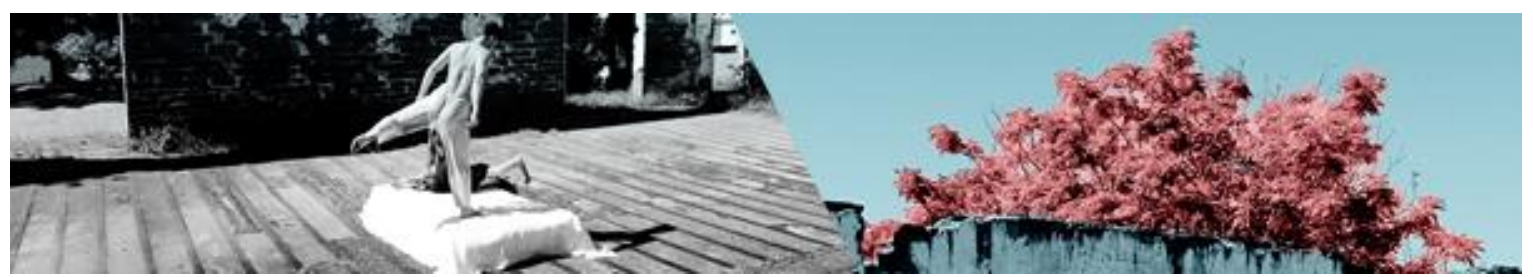

O campo da educação em dança, atualmente, encontra-se bastante influenciado pelo que Louppe (1994) chamou de "nova filosofia do movimento em dança”, que marcou a história da dança contemporânea ao longo do século XX. Tal paradigma pedagógico, que propõe desconstruir um ideal de corpo na dança, enfatizando a experiência subjetiva e cinestésica do corpo em movimento, a criatividade, a autodescoberta e a construção de um corpo "expressivo", pode ter um importante potencial para contribuir para a ruptura de padrões impostos sobre a dança a partir das normas de gênero.

No entanto, é preciso tomar o cuidado de não pressupor uma relação linear e determinista, que reduz a complexidade da ação pedagógica apenas à abordagem didático-metodológica. Pois, quer estejamos falando em modelos ditos 'tradicionais' de ensino de dança, que permitem pouca criatividade, quer estejamos falando de propostas mais contemporâneas, da mesma forma como acontece no campo artístico, nunca se estará isento de reproduzir normas e padrões de gênero.

Esses são elementos que apontam para a relevância do presente artigo: o ensino de dança no ambiente formal e a implicação da dimensão do gênero em uma aula. Sendo a dança uma prática comum a todas as sociedades humanas e o corpo o centro de suas representações estéticas, compreende-se que ela pode ter potencial de intervenção pedagógica no que diz respeito à modificação de valores e de referenciais de gênero. Pode ser uma ferramenta para operar a desconstrução de padrões de comportamento arraigados a partir de representações hegemônicas de gênero e sexualidade.

\section{METODOLOGIA E OBJETIVOS}

Este estudo investigou o comportamento de estudantes de ensino fundamental que participaram de um projeto do Programa Institucional de Bolsas e Iniciação à Docência (PIBID) da Universidade Estadual do Rio Grande do Sul (UERGS), promovido pelo curso de licenciatura em Dança. O PIBID, uma iniciativa sobre a interação entre meninos e meninas em uma aula de dança. Revista da FUNDARTE, Montenegro, p.375-394, ano 19, no 37, Janeiro/Março.

Disponível em: http://.seer.fundarte.rs.gov.br/index.php/RevistadaFundarte/index> 30 de março de 2019. 


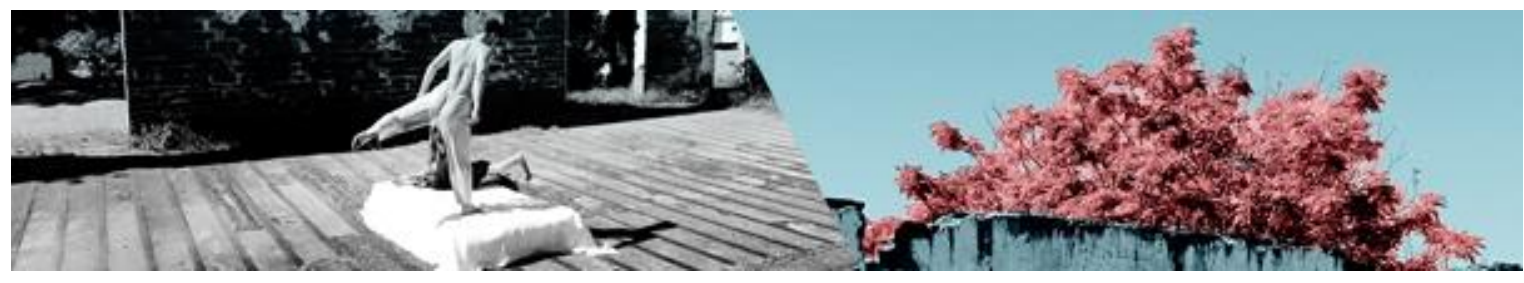

do Governo Federal por intermédio da CAPES - Coordenação de Aperfeiçoamento de Pessoal de Nível Superior atua em nosso país como um meio de inserção de estudantes das licenciaturas das Instituições de ensino superior (IES) nas escolas de educação básica da rede pública de ensino. Tem como objetivo o desenvolvimento de atividades didático-pedagógicas pelos licenciandos, orientadas por professores da Universidade.

A partir de uma metodologia de pesquisa qualitativa, de inspiração etnográfica e com o uso da observação participante, procuramos enfocar as relações de gênero em aulas de dança. O período de observação transcorreu ao longo de quatro meses, período de intervenção pedagógica organizado para a intervenção dos bolsistas.

A pesquisa teve como objetivo geral observar, nas falas e comportamentos dos alunos e professores, situações que possam ter articulações com as questões de gênero. Dentro disso, inclui-se tanto a análise das relações entre: a) meninos e meninas; b) meninos e meninos; ou c) meninas e meninas. Preconizou-se, também d) a análise da atuação didático-metodológica do(a) professor(a), com o intuito de problematizar o papel que ele pode desempenhar em relação às questões de gênero.

Neste sentido, a pesquisa objetivou identificar em que medida se reproduzem relações de poder, normas e valores culturais hegemônicos de gênero e em que medida existe resistência a eles nas aulas de dança. Enfim, analisou o quanto as aulas de dança podem funcionar como instâncias tanto de reprodução das normas hegemônicas de gênero e sexualidade, quanto de um espaço para a sua problematização crítica, ou suas resistências. Pretendeu-se, com isto, contribuir para a reflexão permanente das questões de gênero na formação docente de professores de dança nas universidades.

O campo de pesquisa foi a Escola Estadual José Pedro Steigleder, localizada no município de Montenegro, no Rio Grande do Sul. O perfil dos professores participantes do Programa e ministrantes das aulas foram alunos que estão cursando a licenciatura em dança na Universidade Estadual do Rio Grande do Sul. Os alunos que freqüentaram as aulas foram jovens adolescentes da turma de

ANDREOLI, Giuliano Souza; CANELHAS, Larissa. A dança e as relações de gênero: uma reflexão sobre a interação entre meninos e meninas em uma aula de dança. Revista da FUNDARTE, Montenegro, p.375-394, ano 19, ํo 37, Janeiro/Março.

Disponível em: http://seer.fundarte.rs.gov.br/index.php/RevistadaFundarte/index> 30 de março de 2019. 


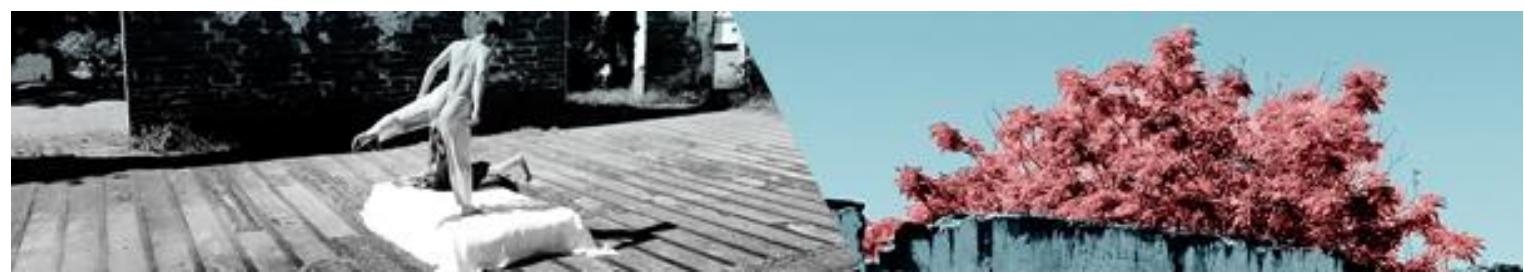

aceleração do $8^{\circ}$ e $9^{\circ}$ ano, que repetiram o ano letivo em alguma série do Ensino Fundamental. São todos alunos de classe popular, de perfil étnico-racial variado e incluem tanto meninos quanto meninas. As observações foram registradas em um diário de campo e depois analisadas.

\section{RESULTADOS E DISCUSSÃO:}

A turma observada continha inicialmente 15 alunos matriculados, mas duas meninas desistiram e uma terceira se afastou por licença-maternidade. A professora desenvolveu atividades variadas, com o objetivo de proporcionar aos alunos a exploração de suas qualidades de movimentos corporais, em conformidade com os conteúdos e propostas curriculares da área da dança.

Um dos exercícios propostos pela professora consistia em os alunos se posicionarem em círculo e arremessarem, entre si, de forma aleatória, bolinhas coloridas. Cada cor de bola correspondia a uma ação ou movimento corporal, a ser executado depois, no centro da roda. Durante a execução deste exercício, observouse que os meninos passavam mais as bolinhas para outros meninos, para a professora e para a pesquisadora-observadora. E que as meninas eram muitas vezes esquecidas, como se também não estivessem na roda. $\mathrm{O}$ que evidenciou a existência de um nível de exclusão que, apesar de ser em grande medida, talvez inconsciente, refletiu a existência de uma hierarquização presente nos modelos de socialização da relação entre meninos e meninas.

Em outra atividade coletiva, desenvolvida com a mesma turma, que consistia em um jogo também realizado em círculo, onde os alunos deveriam estar atentos para receber uma bola imaginária dos colegas e passá-la adiante, olhando nos olhos daquele para quem fosse passá-la, também foi constatada diferenças nos comportamentos entre os dois sexos. Como se tratava de um jogo de disputa, onde aqueles que errassem os movimentos ou não os executassem a tempo saíam da roda, percebemos que as meninas erravam mais, e saíam primeiro, logo nas primeiras rodadas da brincadeira.

ANDREOLI, Giuliano Souza; CANELHAS, Larissa. A dança e as relações de gênero: uma reflexão sobre a interação entre meninos e meninas em uma aula de dança. Revista da FUNDARTE, Montenegro, p.375-394, ano 19, no 37, Janeiro/Março.

Disponível em: http://.seer.fundarte.rs.gov.br/index.php/RevistadaFundarte/index> 30 de março de 2019. 


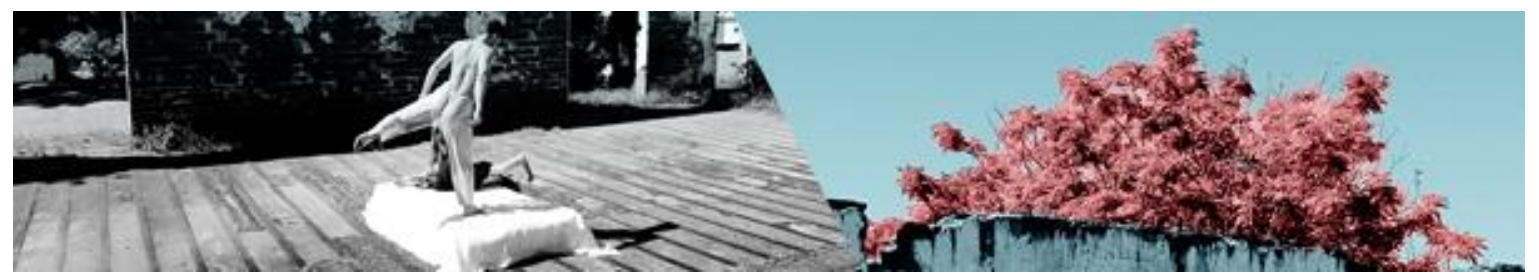

De forma similar às observadas aqui, a bibliografia internacional também tem apontado significativas diferenças de gênero na participação de alunos e alunas em aulas de dança. Um estudo de Willis (1995), com 800 meninos e meninas em um programa de dança em uma escola fundamental nos EUA, constatou que os meninos ocupam áreas maiores do espaço, usam mais energia física, movem-se mais rápido, aceitam mais riscos físicos em aulas de dança. Já as meninas trabalham em um espaço mais limitado, movem-se em um tempo mais moderado, não assumem riscos físicos e dispendem de um tempo considerável permanecendo paradas e apreensivas para se mostrarem.

Louro (2007, p.11) destaca que as identidades de gênero e sexuais são compostas e definidas por relações sociais, "moldadas pelas redes de poder de uma sociedade". O comportamento de um corpo, durante uma aula de dança, revela como certas hierarquias sociais entre os universos simbólicos, considerados como "masculino" e "feminino", se constituem em nossa cultura. Assim, é importante considerar que existe todo um aparato de discursos que produzem o corpo-menino como um corpo que apresenta naturalmente um aparato fisiológico mais apto para funcionar mais ativamente.

Em uma terceira atividade, foi proposto que os alunos e alunas caminhassem pela sala com bastões nas mãos e que, ao comando súbito da professora, deveriam colocar-se em posição para oferecer resistência física, pressionando, em duplas, um bastão contra o outro. $O$ objetivo era trabalhar a atenção voltada para o estado de prontidão corporal necessário para uma reação rápida, importante para potencializar a expressividade do corpo na dança. Foi observado que as meninas não se separavam durante o deslocamento livre pela sala, permanecendo sempre umas no rastro umas das outras. De forma que, quando a professora batia palmas, dando o sinal para formarem as duplas, as meninas sempre tendiam a permanecer juntas, evitando, assim, realizar o exercício com os meninos.

Com isso, fica evidente uma questão muito discutida no âmbito dos estudos sobre gênero na educação, que é dificuldade de integrar meninos e meninas nas mesmas atividades. No mesmo estudo de Willis (1995), citado anteriormente, o autor

ANDREOLI, Giuliano Souza; CANELHAS, Larissa. A dança e as relações de gênero: uma reflexão sobre a interação entre meninos e meninas em uma aula de dança. Revista da FUNDARTE, Montenegro, p.375-394, ano 19, no 37, Janeiro/Março.

Disponível em: http://.seer.fundarte.rs.gov.br/index.php/RevistadaFundarte/index> 30 de março de 2019. 


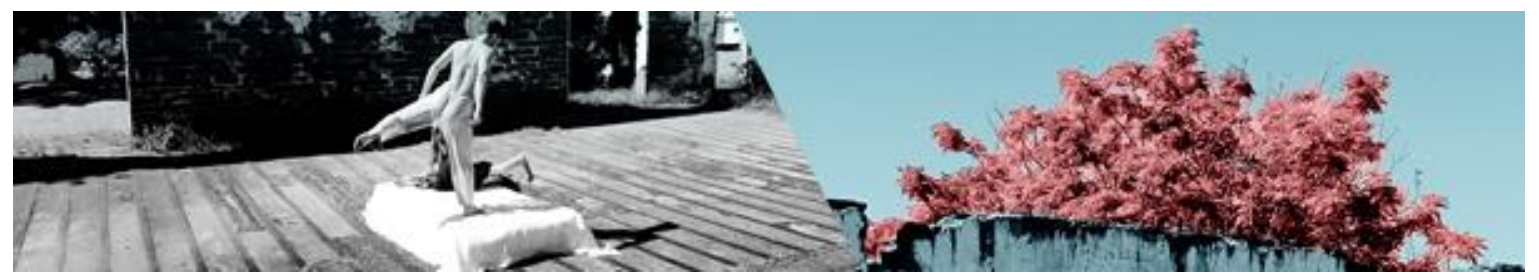

observou que, quando se trabalha com turmas mistas, os meninos assumem posições de liderança com facilidade, e as garotas queixam-se frequentemente que os meninos não cooperam com elas. A partir da observação de uma das situações com o mesmo exercício dos bastões, descrito anteriormente, evidenciou-se que tal separação espacial e corporal se deu, no contexto observado, pelo fato das meninas não esperarem a cooperação dos meninos:

Durante a sequência, uma menina e um menino fazem duplas de força de resistência usando bastões. A menina é muito maior que o menino e demonstra ter mais força. O menino aumenta o seu tônus e não permite que a menina aparente ter mais força, empurrando-a para trás. Sua oposição é tão rápida que terminam os dois derrubando os bastões no chão. (Diário de Campo).

Louro (2013) afirma que o gênero atravessa as pedagogias inseridas na sociedade para a construção dos corpos "educados" dentro de certas normas. Entende-se por "educados" os corpos que são nutridos e constituídos de imersões das práticas culturais e históricas sociais. Para Louro (2007, p.16), "ao classificar os sujeitos, toda sociedade estabelece divisões e atribui rótulos que pretendem fixar as identidades. Ela define, separa e, de formas sutis ou violentas, também distingue e discrimina". A partir dos contextos descritos acima, é possível perceber que essas formas sutilmente violentas de delimitar fronteiras físicas e simbólicas entre 0 universo masculino e o feminino estão presentes nas dinâmicas corporais praticadas nas aulas de dança.

Estudos sobre masculinidades (KIMMEL, 1998; CONNEL, 2013) observam que os modelos hegemônicos ainda pautam-se por características, tais como: competição, individualidade, hierarquia, dominação e força corporal. Todavia, é importante ressaltar que a construção da masculinidade hegemônica não segue um eixo fixo e unificado, e a hegemonia pode ser mutável, dependendo do contexto e do arranjo sócio-cultural. Nesta linha de problematização, os meninos que frequentaram as aulas de dança observadas, confrontados com a configuração didática de uma aula mista, onde as atividades não eram diferenciadas para cada sexo, demarcaram

ANDREOLI, Giuliano Souza; CANELHAS, Larissa. A dança e as relações de gênero: uma reflexão sobre a interação entre meninos e meninas em uma aula de dança. Revista da FUNDARTE, Montenegro, p.375-394, ano 19, ํo 37, Janeiro/Março.

Disponível em: http://.seer.fundarte.rs.gov.br/index.php/RevistadaFundarte/index> 30 de março de 2019. 


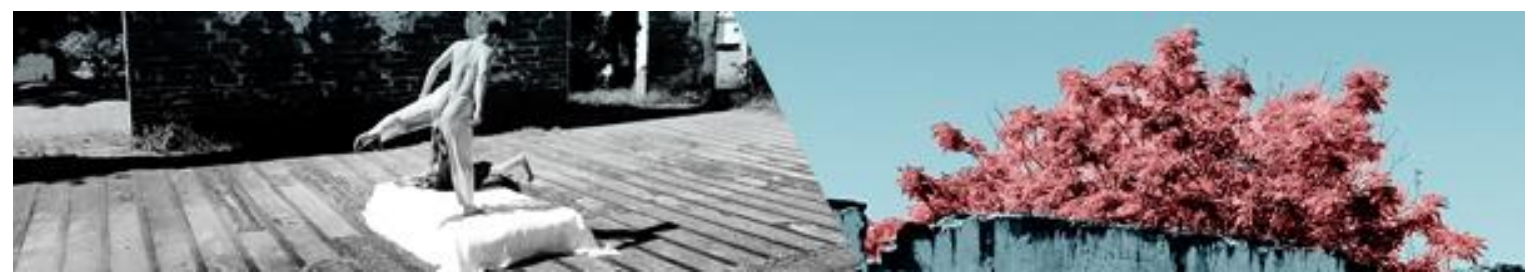

esta diferença entre o universo masculino e o feminino, reforçando os atributos daquilo que Connel (1995) chama de "masculinidade hegemônica".

Vários estudos têm demonstrado que, embora muitas vezes inicialmente intimidados por se envolverem em uma prática que a sociedade percebe como "feminina", uma vez que dancem profissionalmente nas companhias e grupos artísticos, os homens experimentam vários privilégios, comparados às mulhes: melhores salários, papéis de maior prestígio na cena ou cargos mais altos. (MEGLIN \& BROOKS, 2012; WRIGHT, 2013; RISNER, 2014; ALLEN-COLLINSON, CLEGG e OWTON, 2016). As relações de poder estabelecidas entre meninos e meninas em sala de aula estão relacionadas às relações de poder observáveis no mundo mais amplo da sociedade. E os meninos reproduzem em suas atitudes, em menor escala, o que a sociedade, como um todo, reproduz a partir de valores culturais hierárquicos.

Nas atividades não competitivas, quando a professora solicitou a construção de partituras coreográficas a partir de movimentos e de gestos corporais de criação livre, observou-se que os meninos geralmente tomavam a iniciativa primeiro. $E$ as meninas ficavam observando, sem interromper ou acrescentar. Nessas aulas, os meninos e meninas também tendiam, muitas vezes, a uma separação em dois grupos. Neste caso, como nos outros descritos anteriormente, a professora não interveio.

Outra situação evidenciada nessa pesquisa refere-se ao dia em que a professora propôs a criação de movimentos com qualidade suave, leve e delicada. Os meninos ofereceram uma grande resistência para executar a tarefa proposta. Inicialmente se negaram a executá-la, dizendo que só as meninas deveriam fazer isto. Saraiva (2013) discute em seu estudo esta questão dos movimentos de dança que podem ou não ser realizados por meninos e meninas a fim de não "perderem suas identidades sexuais".

Aqui, vale também ressaltar o papel que a professora tenta desempenhar em relação às questões de gênero. É importante observar que desde o início, no planejamento da atividade, ela não tenta operar com a noção de diferenciação entre

ANDREOLI, Giuliano Souza; CANELHAS, Larissa. A dança e as relações de gênero: uma reflexão sobre a interação entre meninos e meninas em uma aula de dança. Revista da FUNDARTE, Montenegro, p.375-394, ano 19, no 37, Janeiro/Março.

Disponível em: http://.seer.fundarte.rs.gov.br/index.php/RevistadaFundarte/index> 30 de março de 2019. 


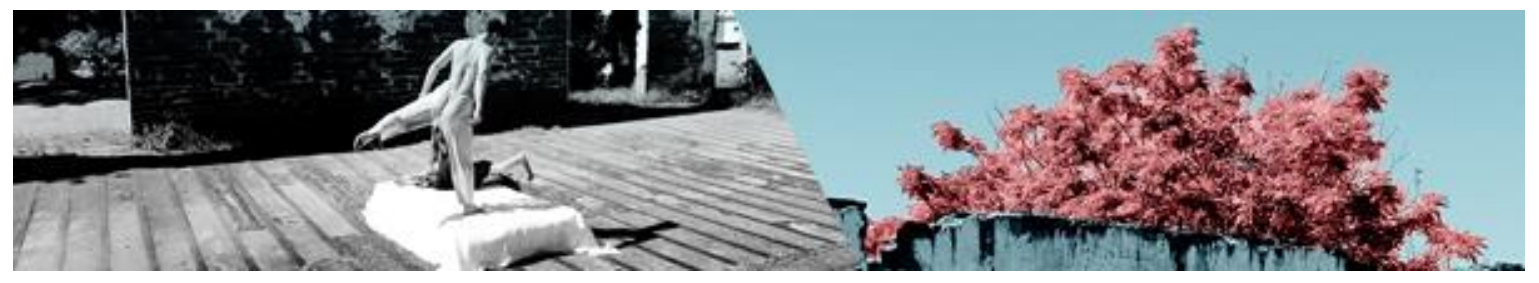

movimentos "femininos" e movimentos "masculinos". Isto cria um conflito entre o que ela propõe e o que provavelmente os meninos têm como referencial. Mas, neste caso, diferente dos outros, a professora intervém pedagogicamente. $E$ ela faz isto marcando a sua posição ao dizer que todos terão que trabalhar com todas as qualidades de movimentos.

Em outra situação, em um exercício corporal, a professora propôs que os alunos criassem gestos que demonstrem estarem apaixonados. Aqui, as meninas tomaram a dianteira, assumindo mais iniciativa do que os meninos. Além disso, as meninas criaram gestos muito diferentes e variados entre si. Os meninos, ao contrário, repetiram mais ou menos, os movimentos uns dos outros, com menor variabilidade.

Alguns estudos (SANTOS, 2008a; SANTOS 2008b) têm observado que, ao serem socializados dentro de uma cultura com forte binarismo de gênero, os homens e as mulheres na dança sempre tenderão a perpetuar a dicotomia dos gêneros ao significar certas danças, ou certos conjuntos de gestos, movimentos corporais ou figurinos como "femininos" ou "masculinos". Essa pressuposição, bastante arraigada no senso-comum, de que existe um jeito "masculino" e um jeito "feminino" de dançar, já dados pela natureza, contrapõe-se às evidências trazidas pelos Estudos de Gênero.

Estes estudos evidenciam que construções simbólicas que limitam as possibilidades estéticas do corpo na dança, colocando a expressividade do corpo dentro de uma oposição binária, não estão dissociadas de outras dimensões da vida dos indivíduos, relacionadas a certas atitudes pessoais, ao status social e até mesmo à posição econômica. Isso é demonstrado nos estudos já citados, mas também nos de Souza (2007) e Andreoli (2011) em companhias profissionais de dança artística, o que demonstra que os significados culturais que interpretam certos movimentos e gestos em dança, a partir da lente do gênero, se articulam a certos valores e expectativas que se referem à posição e ao comportamento de homens e mulheres em sociedade.

ANDREOLI, Giuliano Souza; CANELHAS, Larissa. A dança e as relações de gênero: uma reflexão sobre a interação entre meninos e meninas em uma aula de dança. Revista da FUNDARTE, Montenegro, p.375-394, ano 19, ํo 37, Janeiro/Março.

Disponível em: http://.seer.fundarte.rs.gov.br/index.php/RevistadaFundarte/index> 30 de março de 2019. 


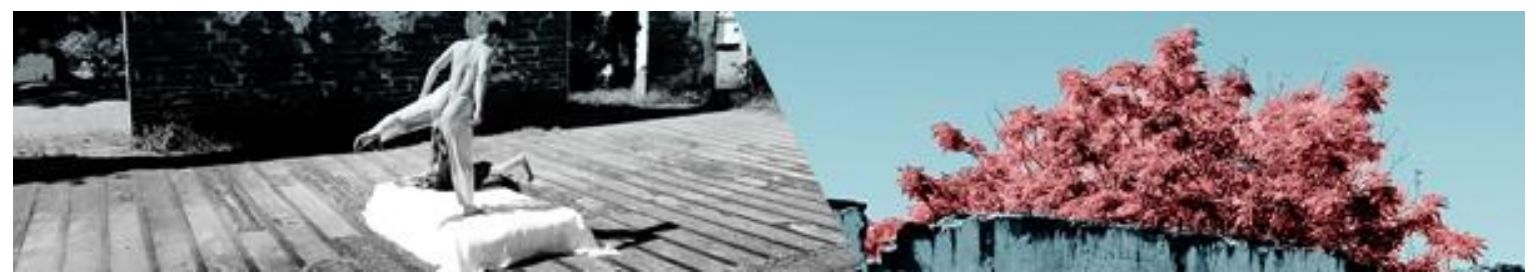

Muitos dias depois, pela insistência da professora, os meninos já aceitavam executar os movimentos mais suaves, leves e delicados. No entanto, é importante ressaltar, eles não os executaram de forma muito nítida, isto é, com a mesma intensidade ou dedicação do que quando executam os movimentos mais fortes e firmes, que provavelmente consideraram mais "masculinos". E mesmo quando já executavam os movimentos suaves e delicados sem reclamar, demonstrando mais naturalidade, eles ainda o fizeram de uma forma muito tímida, demonstrando estarem envergonhados.

Em outra situação observada por este estudo, a professora propôs que os alunos e alunas construíssem uma coreografia a partir do trabalho que vinham desenvolvendo até então, para apresentarem na Mostra de Dança que haveria na escola no final do semestre. Este evento, criado pelos professores bolsistas do projeto PIBID, possuía a frequência de uma vez por mês. Os meninos prontamente responderam que não queriam apresentar. Já as meninas responderam que, para elas, tanto fazia apresentar ou não.

Em outra aula, depois de transcorridos dois meses de atividades, um dos meninos demonstrou estar mais motivado para a execução das atividades de dança propostas. Ele posicionou-se na frente dos outros, demonstrou maior concentração e interesse ao executar os movimentos. Mas o tempo todo olhava para trás e tentava reparar na reação dos colegas meninos, que olhavam para ele. Depois do término da aula, este mesmo aluno, que havia antes demonstrado interesse em apresentar a coreografia na mostra de Dança da escola, concordou com seus amigos e disse que não ia mais apresentar.

Aqui, evidencia-se o caráter relacional (SCOTT, 1995) das construções identitárias de gênero e o quanto a validação e a legitimação da "verdadeira" masculinidade autêntica se dão a partir da relação com os outros meninos. $O$ interesse pela dança parece colocar a masculinidade deste menino sob suspeita diante dos demais. E evidencia-se o caráter ativo da própria atuação das normas reguladoras de gênero, pois, mesmo tendo demonstrado gostar de dançar, no final o menino não quis se apresentar por conta da expectativa sobre o julgamento dos

ANDREOLI, Giuliano Souza; CANELHAS, Larissa. A dança e as relações de gênero: uma reflexão sobre a interação entre meninos e meninas em uma aula de dança. Revista da FUNDARTE, Montenegro, p.375-394, ano 19, no 37, Janeiro/Março.

Disponível em: http://.seer.fundarte.rs.gov.br/index.php/RevistadaFundarte/index> 30 de março de 2019. 


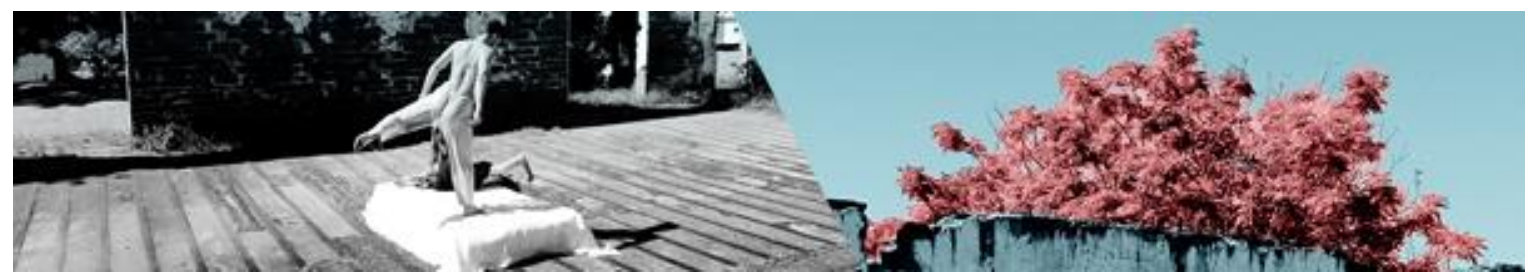

outros meninos. Neste contexto social evidencia-se um investimento ativo na regulação de modos de ser masculino na dança, através do policiamento das posturas, dos movimentos, dos gestos, dos figurinos, etc, mesmo quando não há nenhuma cobrança verbalizada.

\section{CONCLUSÃO:}

A escrita deste artigo teve por objetivo contribuir para a reflexão pedagógica no campo da dança, a partir da contribuição que os estudos de gênero propõem para o campo geral da educação. O estudo demonstrou que, em aulas de dança, as relações sociais entre meninos e meninas refletem as hierarquias entre homens e mulheres existentes na sociedade, dificultando a sua interação em turmas mistas e expressando, muitas vezes, situações de micro-violências, com a sutil exclusão das meninas. E que, muitas vezes, os professores se colocam de forma neutra diante da reprodução dessas hieraquias sociais. O que aponta para a importância da reflexão pedagógica sobre o tema e dos(as) professores(as) estarem atentos para a sensibilização das percepções de estudantes de dança sobre as desigualdades de gênero dentro das aulas de dança.

O estudo também evidenciou que o gênero constrói significados diferenciados para meninos e meninas sobre a vivência e a experiência corporal com a dança, mesmo quando estão sendo aplicadas metodologias mais contemporâneas, que permitem uma maior liberdade na criação de movimentos. Nos exemplos das situações observadas, os(as) professores(as) estimularam a transposição dos padrões corporais impostos pelas normas de gênero. Estas atitudes, no entanto, limitaram-se à atuação sobre os meninos, que, desde o início, apresentavam em seu perfil maiores limitações na criatividade, o que, por sua vez, representou uma relativização importante de noções de "feminização" de algumas qualidades de movimento de dança, permitindo aos meninos dançarem fora das normas de gênero, tencionando, assim, padrões de masculinidade dominantes.

ANDREOLI, Giuliano Souza; CANELHAS, Larissa. A dança e as relações de gênero: uma reflexão sobre a interação entre meninos e meninas em uma aula de dança. Revista da FUNDARTE, Montenegro, p.375-394, ano 19, no 37, Janeiro/Março.

Disponível em: http://.seer.fundarte.rs.gov.br/index.php/RevistadaFundarte/index> 30 de março de 2019. 


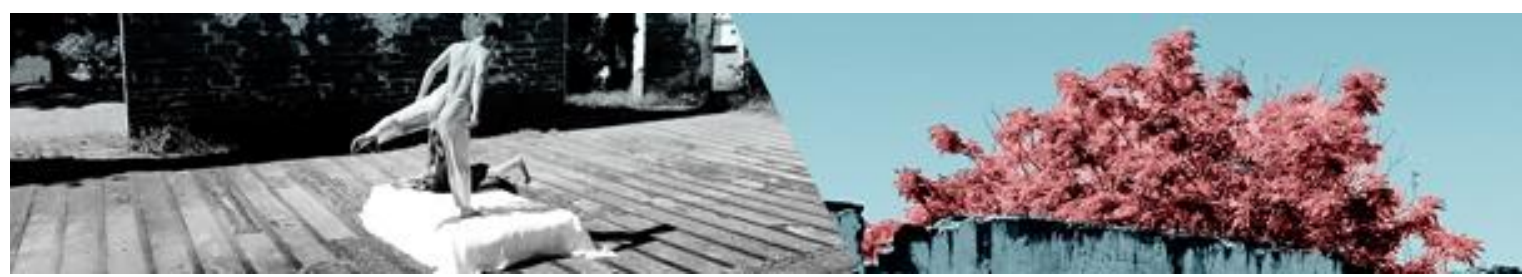

O estudo aponta caminhos para a potencialidade de um ensino de dança mais atento à diversidade, no que tange às questões de gênero. E evidencia que qualquer perspectiva de ensino da dança que se proponha consciente e responsável deve levar em conta o complexo processo da construção do gênero, a partir do qual a dança pode muitas vezes funcionar como um mecanismo de perpetuação de padrões culturais. Atitudes aparentemente insignificantes, como ensinar para os alunos que existem movimentos de dança mais "masculinos" e mais "femininos" pode contribuir para perpetuar concepções limitadas de gênero, ligadas à produção de práticas sociais sexistas, heteronormativas ou transfóbicas. Os professores de dança têm um papel importante a desempenhar, nesse sentido. E é importante que a sua atuação didático-metodológica tenha sempre a preocupação de problematizar que papel ele(ela) pode desempenhar em relação a uma educação voltada para a pluralidade.

\section{Referências:}

ALLEN-COLLISON, Jacquelyn, CLEGG, Helen; e OWTON, Helen. The "cool stuff: Gender, dance ans masculinity. Psychology of Women's Section Review, Special Issue on Sports, v.18, n.2, p6-16, 2016.

ANDREOLI, Giuliano Souza. Representações de masculinidade na dança contemporânea. Revista Movimento, v. 17, n. 01, p. 159-175, 2011.

ANDREOLI, Giuliano Souza. A Técnica Corporal na Dança: redimensionamentos epistemológicos. Revista Arte da Cena, Goiânia, v.3, n.2, p.89-111, jul-dez, 2017.

ANDREOLI, Giuliano Souza. Dança, gênero e sexualidade: narrativas e performances. Novas Edições Academicas, Beau Bassim, Mauritius, 2018.

BEAUVOIR, Simone de. O Segundo Sexo. Volume 2: A experiência vivida. Difusão Européia do Livro, São Paulo, 1967.

BERGHAUSER, Tatiana Araújo. Problematizações sobre enfoques de gênero reducionistas ou distorcidos na Dança. Artigo (especialização). Programa de Pósgraduação em Dança, UFBA, Salvador, 2013.

ANDREOLI, Giuliano Souza; CANELHAS, Larissa. A dança e as relações de gênero: uma reflexão sobre a interação entre meninos e meninas em uma aula de dança. Revista da FUNDARTE, Montenegro, p.375-394, ano 19, ํo 37, Janeiro/Março.

Disponível em: http://.seer.fundarte.rs.gov.br/index.php/RevistadaFundarte/index> 30 de março de 2019. 


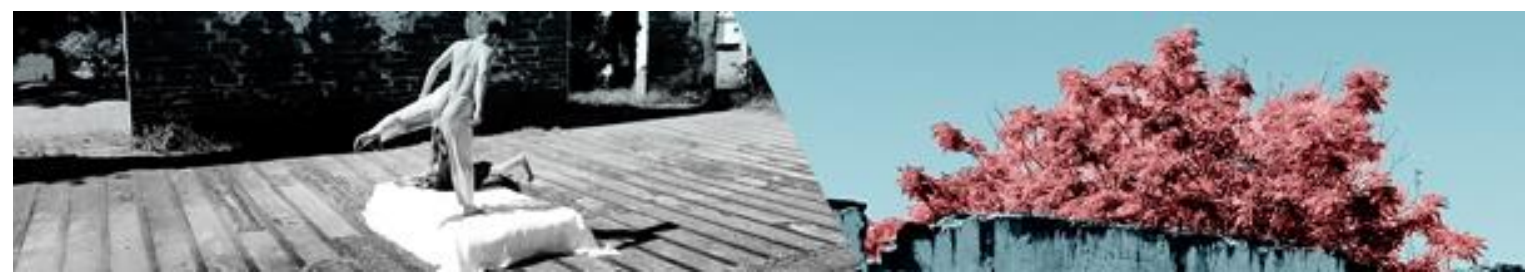

BRITZMAN, Deborah. O que é esta coisa chamada amor? - identidade homossexual, educação e currículo. Revista Educação e Realidade, Porto Alegre, vol. 21, n.1, p.71-76, jan-jun, 1996.

BUTLER, Judith. Corpos que pesam: sobre os limites discursivos do "sexo". In: LOURO, Guacira Lopes (org). O corpo educado: pedagogias da sexualidade. Belo Horizonte: Autêntica, 2001.

BUTLER, Judith. Problemas de gênero: feminismo e subversão da identidade. Rio de Janeiro: Civilização Brasileira, 2010.

CONNEL, Robert William. Políticas de Masculinidade. Educação e Realidade. V.20, n.2, jul/dez, p.185-206, 1995.

CONNEL, Robert William \& MESSERSCHMIDT, James. Masculinidade hegemônica: repensando o conceito. Estudos Feministas, Florianópolis, v. 21, n.1, p.424, janeiro/abril, 2013.

CORREIA, Clara Pinto. O Testículo esquerdo: alguns aspectos da demonização do feminino, Lisboa: Relógio D'Água Editores, 2004.

CLIFFORD, James. On Ethnographic Allegory" in Cliffor, James e Jeorge Marcus (orgs.), Writing Cultures: The Poetics and Politics of Ethnography, Berkeley, Los Angeles, Lonfdon: University of California Press. 1986.

HANNA. Judith Lynne. Dança, Sexo e Gênero: signos de identidade, dominação, desafio e desejo. Tradução: Mauro Gama. Rio de Janeiro: Rocco, 1999.

HOLDSWORTH, Nadine. 'Boys don't do dance, do they?', Research in Drama Education: The Journal of Applied Theatre and Performance, v.18, n.2, p.168178, 2013.

JESUS, Jaqueline Gomes de. Orientações sobre identidade de gênero: conceitos e termos. Brasília. 42 p., 2012.

KIMMEL, Michael Scott. A produção simultânea de masculinidades hegemônicas e subalternas. In: Horizontes Antropológicos. Corpo, doença e saúde. Porto Alegre: PPGAS/UFRGS, ano 4, n.9, out, p.103-17, 1998.

LAQUEUR, Thomas Walter. Inventando o Sexo: corpo e gênero dos gregos a Freud. Tradução: Vera Whately. Rio de Janeiro: Relume Dumará, 2001.

LOURO, Guacira Lopes. Gênero, Sexualidade e Educação: uma perspectiva pósestruturalista. Rio de Janeiro: Vozes, 2007.

ANDREOLI, Giuliano Souza; CANELHAS, Larissa. A dança e as relações de gênero: uma reflexão sobre a interação entre meninos e meninas em uma aula de dança. Revista da FUNDARTE, Montenegro, p.375-394, ano 19, no 37, Janeiro/Março.

Disponível em: http://.seer.fundarte.rs.gov.br/index.php/RevistadaFundarte/index> 30 de março de 2019. 


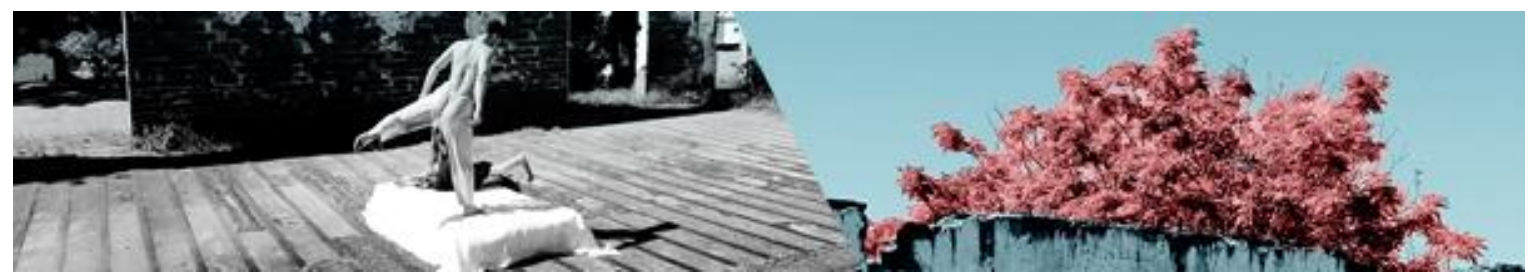

LOURO, Guacira Lopes. (Org.) O corpo educado: pedagogias da sexualidade. Belo Horizonte: Autêntica Editora, 2013a.

LOURO, Guacira Lopes. Um corpo estranho: ensaios sobre sexualidade e teoria queer. Belo Horizonte: Autêntica Editora, 2013b.

MAUSS, Marcel. As Técnicas Corporais. In: Sociologia e Antropologia. vol. 2. São Paulo: E.P.U./EDUSP, 1974.

MEGLIN, Joellen. A., \& BROOKS, Lynn Matluck. Where are all the women choreographers in ballet? Dance Chronicle, v. 35, n.1, p.1-7, 2012.

MIGDALEK, Jack. The Embodied Performance of Gender, v.43, London, United Kingdom: Routledge, 2015.

MEYER, Dagmar Estermann. Gênero, Sexualidade e Educação: Teoria e Política. In: LOURO, G.L., NECKEL, J.F. \& GOELLNER, S.V. (Orgs). Corpo, gênero e sexualidade: um debate contemporâneo em Educação. Petrópolis, RJ: Editora Vozes, p.9-27, 2003.

NICHOLSON, Linda. Interpretando o gênero. Revista Estudos Feministas. Vol. 8 (2), 2000.

PASCOE, Cheri J. 'Dude, You're a Fag': adolescent masculinity and the fag discourse, Sexualities, v.8, n.3, p.329-346, 2005.

POLASEK, Katherine M. \& ROPER, Emily A. Negotiating the gay male stereotype in ballet and modern dance. Research in Dance Education, v. 12, n.2, p.173-193, 2011.

PRECIADO, Beatriz. Manifesto Contrassexual. Políticas subversivas de identidade sexual. São Paulo, n.1. Edições, 2014.

RISNER, Doug. Bullying victimisation and social support of adolescent male dance students: an analysis of findings. Research in Dance Education, v.15, n.2, p.179-201, 2014.

SANDERSON, Patrícia. Age and gender issues in adolescente attitudes to dance. European Physical Education Review, v.7, n2, p. 117-136, 2001.

SCOTT, Joan. Gênero: Uma categoria útil de análise histórica. Educação e Realidade. Porto Alegre, UFRGS, v.20, n.2, p.71-79, 1995.

SANTOS, Éderson Costa. Um jeito masculino de dançar: pensando a produção das masculinidades de dançarinos de hip-hop. 124 f. Dissertação (Mestrado) - Programa de Pós-Graduação em Educação, UFRGS, Porto Alegre, 2009a.

ANDREOLI, Giuliano Souza; CANELHAS, Larissa. A dança e as relações de gênero: uma reflexão sobre a interação entre meninos e meninas em uma aula de dança. Revista da FUNDARTE, Montenegro, p.375-394, ano 19, no 37, Janeiro/Março.

Disponível em: http://.seer.fundarte.rs.gov.br/index.php/RevistadaFundarte/index> 30 de março de 2019. 


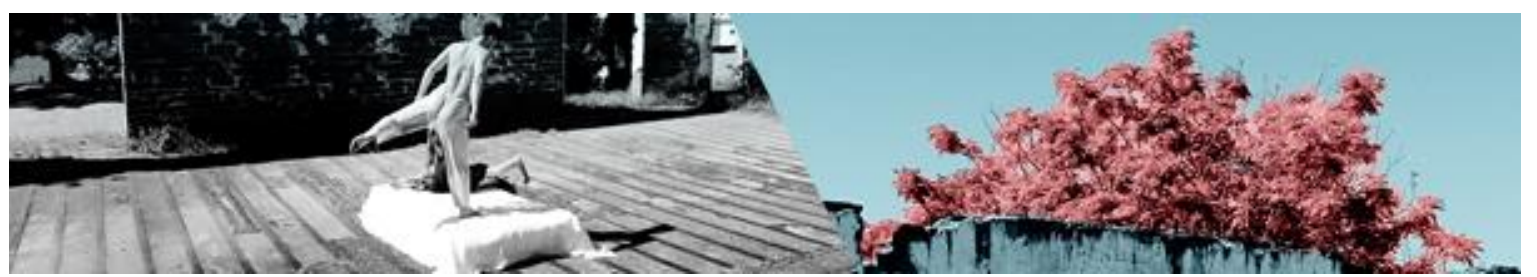

SANTOS, Tatiana Mielczarski. Entre pedaços de algodão e bailarinas de porcelana: a performance artística do balé clássico como performance de gênero. $95 \mathrm{f}$. Dissertação (Mestrado) - Programa de Pós-graduação em Educação, UFRGS, Porto Alegre, 2009b.

SOUZA, Andréa Bittencourt de. Cenas do masculino na dança: representações de gênero e sexualidade. Ensinando modos de ser bailarino. Dissertação (Mestrado), Programa de Pós-graduação em Educação, ULBRA, Canoas, 2007.

STINSON, Susan. The hidden curriculum of gender in dance education. Journal of Dance Education. v.5 , n.2, p.51-57, 2005.

WELLER, Wivian. A presença feminina nas (sub) culturas juvenis: a arte de se tornar visível. Revista Estudos Feministas, Florianópolis, v.1, ano 13, p. 107-126, jan./abr. 2005.

WILLIS, Cheryl M. Factors thar affect dance programs. Journal of Physical Education. Recreation e Dance, v.66 (n.4). P. 58-63, 1995.

WRIGHT, Jan. Male dance educators in a female-dominated profession, Journal of Physical Education, Recreation \& Dance, v. 84, n.7, p.14-15, 2013.

ANDREOLI, Giuliano Souza; CANELHAS, Larissa. A dança e as relações de gênero: uma reflexão sobre a interação entre meninos e meninas em uma aula de dança. Revista da FUNDARTE, Montenegro, p.375-394, ano 19, no 37, Janeiro/Março.

Disponível em: http://seer.fundarte.rs.gov.br/index.php/RevistadaFundarte/index> 30 de março de 2019. 